\title{
Lower serum magnesium is associated with vascular calcification in peritoneal dialysis patients: a cross sectional study
}

\author{
Amber O. Molnar ${ }^{1}$, Mohan Biyani', Ian Hammond ${ }^{2,3}$, John Paul Harmon", Susan Lavoie ${ }^{1}$, Brendan McCormick', \\ Manish M. Sood ${ }^{1,5}$, Jessica Wagner ${ }^{4}$ Elena Pena ${ }^{2,3}$ and Deborah L. Zimmerman ${ }^{1,5,6^{*}}$
}

\begin{abstract}
Background: Coronary artery calcification (CAC) is highly prevalent among dialysis patients and is associated with increased cardiovascular and all cause mortality. Magnesium (Mg) inhibits vascular calcification in animal and in-vitro studies but whether the same effect occurs in humans is uncertain.

Methods: A single centre cross-sectional study of 80 prevalent peritoneal dialysis (PD) patients; on PD only for a minimum of 3 months. A radiologist blinded to patient status calculated their abdominal aortic calcification (AAC) scores on lateral lumbar spine radiographs, a validated surrogate for CAC.

Results: Eighty patients provided informed consent and underwent lumbar spine radiography. The mean serum Mg was $0.8 \mathrm{mmol} / \mathrm{L}$ (standard deviation 0.2) and mean AAC score 8.9 (minimum 0, maximum 24). A higher serum Mg level was associated with a lower AAC score $\left(R^{2}=0.06\right.$, unstandardized coefficient $\left.[B]=-7.81, p=0.03\right)$, and remained after adjustment for age, serum phosphate, serum parathyroid hormone, low-density lipoprotein cholesterol, smoking history, and diabetes (model adjusted $R^{2}=0.36$, serum Mg and AAC score $B=-11.44, p=0.00$ ). This translates to a $0.1 \mathrm{mmol} / \mathrm{L}$ increase in serum $\mathrm{Mg}$ being independently associated with a 1.1-point decrease in AAC score.

Conclusions: Our findings suggest that Mg may inhibit vascular calcification. If this association is replicated across larger studies with serial Mg and vascular calcification measurements, interventions that increase serum Mg and their effect on vascular calcification warrant further investigation in the PD population.
\end{abstract}

Keywords: Magnesium, Peritoneal dialysis, Vascular calcification

\section{Background}

The mortality rate of patients on dialysis is in excess of $20 \%$ per year, with approximately one half of deaths attributable to cardiovascular disease [1,2]. Dialysis patients have a high prevalence of traditional cardiac risk factors and experience further risk due to abnormal mineral metabolism [1]. Studies in prevalent hemodialysis (HD) patients have found that $90 \%$ of such patients have coronary artery calcification $(\mathrm{CAC})$, which is associated with increased all cause and cardiovascular mortality [2-4]. Hypercalcemia, hyperphosphatemia, and hyperparathyroidism

\footnotetext{
* Correspondence: dzimmerman@toh.on.ca

${ }^{1}$ Division of Nephrology, Department of Medicine, McMaster University,

Hamilton, ON, Canada

${ }^{5}$ Kidney Research Centre, Ottawa Hospital Research Institute, Ottawa, ON,

Canada

Full list of author information is available at the end of the article
}

have received the most attention; several studies have demonstrated their association with accelerated vascular calcification [5]. However, there has been comparatively little exploration of the association of serum magnesium $(\mathrm{Mg})$ with vascular calcification. Both in-vitro and animal studies have found that the addition of $\mathrm{Mg}$ to vascular smooth muscle cells inhibits the increase in mineralization associated with an osteoblastic phenotype, increases the expression of anti-calcification proteins, and down regulates pathways necessary for the development of vascular calcification [6-12]. The transient receptor potential melastin (TRPM)7 cation channel as well as the $\mathrm{Wnt} / \beta$-catenin pathway are proposed as being essential to $\mathrm{Mg}$ regulating vascular calcification [7, 11]. Small observational studies and pilot studies administering Mg containing phosphate binders in dialysis populations have found a significant 
association between lower serum $\mathrm{Mg}$ levels and the progression of CAC, peripheral arterial calcification, mitral annular calcification, and atherosclerosis of the common carotid artery [13-19]. A recent study demonstrated that a higher serum $\mathrm{Mg}$ significantly decreased the mortality risk associated with hyperphosphatemia in HD patients [20] As well, a lower serum Mg level has been found to be associated with increased mortality in both HD and PD patients [21-27]. These cumulative results suggest a possible association between hypomagnesemia and CAC. The majority of studies have used poorly validated surrogates for CAC, $[3,28]$ and only one study included PD patients, [16] who are at highest risk for hypomagnesemia due to the low $\mathrm{Mg}$ concentration of commonly used PD solutions $[29,30]$. To better characterize the relationship between serum $\mathrm{Mg}$ and CAC in PD patients, we performed a cross sectional study using the degree of abdominal aortic calcification (AAC) seen on a lateral lumbar spine radiograph, a validated and inexpensive surrogate for CAC $[28,31]$.

\section{Methods}

\section{Dialysis prescription}

Patients in the Ottawa Hospital Home Dialysis Program in Ottawa, Ontario, Canada were recruited from 2012 to 2014. These individuals are assessed routinely in a multi-disciplinary clinic every six weeks and recruitment was performed at a regular clinic visit. Included patients had to be on PD for a minimum of three months and had to be capable of providing informed consent. Patients on hybrid therapy (combined HD and PD) were excluded. Because the study was of cross-sectional design, all variables were measured once upon patient enrollment. Our Home Dialysis Program exclusively used PD solutions provided by Baxter Healthcare Corporation (Deerfield, Illinois) during the study period. Solutions used included Dianeal, Extraneal, and rarely Physioneal. Information on these solutions and their composition is available at: http://www.baxter.com/healthcare_professionals/products/index.html\#Renal. Patients are offered a choice between continuous ambulatory peritoneal dialysis and continuous cyclic peritoneal dialysis. The dialysis programs are adjusted to deliver a minimum weekly $\mathrm{Kt} / \mathrm{V}$ urea of 1.7 as per Canadian Society of Nephrology guidelines [32].

\section{Biochemical assays}

At the time of enrolment, a patient's serum calcium (Ca), phosphate (PO4), parathyroid hormone (iPTH), albumin, $\mathrm{Mg}$ and a non-fasting cholesterol profile were measured. All samples were analyzed in the Hospital Laboratory in accordance with the Hospital Laboratory Guidelines. Serum $\mathrm{Ca}$ and PO4 were analyzed with the Siemens Vista 1500 analyzer (Munich, Germany) (coefficient of variation (CV) for Ca $2.63 \%$ at $1.42 \mathrm{mmol} / \mathrm{L}$ and $2.1 \%$ at $2.5 \mathrm{mmol} /$
$\mathrm{L} ; \mathrm{CV}$ for $\mathrm{PO} 43.4 \%$ at $0.6 \mathrm{mmol} / \mathrm{L}$ and $2.4 \%$ at $1.3 \mathrm{mmol} /$ L). iPTH was analyzed using the Beckman Coulter Immunoassay (Brea, California) (CV 6.9\% at $2.6 \mathrm{pmol} / \mathrm{L}$, $6.9 \%$ at $19.9 \mathrm{pmol} / \mathrm{L}$ and $5.8 \%$ at $59.3 \mathrm{pmol} / \mathrm{L}$ ). Serum albumin was analyzed with the Dimension Vista (Siemens, Munich, Germany) system using an adaptation of the bromocresol purple dye binding method (CV 2.5\% at $3.2 \mathrm{~g} /$ dL). Serum Mg was analyzed with the Dimension Vista system using a modification of the methylthymol blue complexometric procedure $(\mathrm{CV} 3 \%$ at $0.78 \mathrm{mmol} / \mathrm{L}$ and $2 \%$ at $1.93 \mathrm{mmol} / \mathrm{L}$ ). Serum total cholesterol, triglycerides and high-density lipoprotein cholesterol (HDL) were measured using the Dimension Vista system (CHOL, TRIG and HDLC methods respectively). Low-density lipoprotein cholesterol (LDL) was calculated using Friedewald's formula. Residual renal function (RRF) was calculated from a 24-h urine collection. Urine creatinine and urine urea were measured; the average of the creatinine clearance and urea clearance was taken to calculate the estimated glomerular filtration rate (eGFR) in $\mathrm{mL} / \mathrm{min}$.

\section{Vascular calcification}

The AAC score was calculated using a lateral lumbar spine radiograph as described by Kauppila et al. from their assessment of 617 Framingham heart study participants [31]. The extent of the calcification of the anterior and posterior aortic wall was graded at each vertebral level from L1 to L4 on a 0-3 scale, yielding three different composite scores. Of these, the antero-posterior severity score, which ranges from 0 to 24 and has the highest inter-rater correlation (intra-class correlation (ICC) 0.93-0.96), was used in our study [31]. This method of determining abdominal aortic calcification has been found to be a valid surrogate for assessing CAC (area under the curve 0.78) $[28,31]$. Each patient had one radiograph performed shortly after his or her enrolment. A radiologist who was blinded to each patient's status interpreted all radiographs. A second independent, blinded radiologist interpreted the abdominal radiographs to confirm the findings of the first radiologist (ICC $=0.99$ (95\% confidence interval 0.980.99)). The ICC was calculated using a two-way mixed effects model with an absolute agreement definition.

\section{Statistical analysis}

Data were summarized as the mean $+/$ - standard deviation or median (interquartile range (IQR)). Univariate linear regression was performed to determine the association of serum $\mathrm{Mg}$ and pre-specified variables of interest with the AAC score. Based on known risk factors for vascular calcification, the following variables were examined in univariate analysis: age (per year), sex, iPTH, serum $\mathrm{Ca}$, serum PO4, calculated LDL cholesterol, total time on dialysis (years), smoking history (ex or current smoker vs non-smoker), diabetes, serum albumin, and RRF. All variables with 
a $p$-value $\leq 0.2$ on univariate regression were adjusted for in the multiple linear regression model. We also performed a multiple linear regression analysis where all pre-specified variables were maintained in the model. Five patients had missing LDL cholesterol values ( $n=1$, no test was performed; $n=4$, triglycerides were too high to calculate LDL). Multiple imputation (SPSS automatic imputation method) was used to impute missing values for LDL in the multiple linear regression analysis. SPSS automatically chooses an imputation method that is most appropriate for the data and uses linear regression to impute missing continuous variables. Five imputed datasets were created and the estimates from each dataset were pooled.

We performed a sensitivity analysis where patients with an aortic calcification score of 0 were removed from the analysis. Patients with very little or no vascular calcification do not tend to develop vascular calcification over time and seem to represent a different subgroup from the general end stage renal disease population [33, 34]. For this reason, we performed a separate analysis to determine the impact upon the overall results. All analyses were performed using SPSS Statistics version 24. The reporting of this study follows the STROBE guidelines for observational studies [35].

\section{Results}

\section{Baseline characteristics}

Eighty six patients provided informed consent; 80 patients completed a lateral lumbar X-ray and were included in the primary analysis. Patient selection is outlined in Fig. 1. The baseline characteristics of included patients are

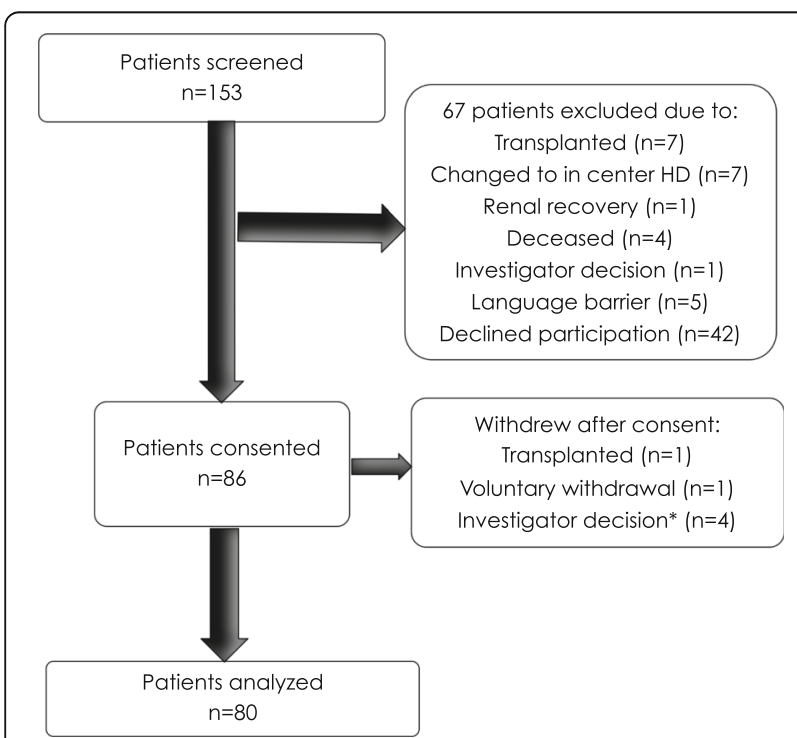

Fig. 1 Patient selection. *These patients consented to participate but then failed to complete the required lumbar $\mathrm{x}$-ray despite multiple reminders
Table 1 Baseline characteristics

\begin{tabular}{|c|c|}
\hline \\
\hline \multicolumn{2}{|l|}{$\frac{\text { lotal } N=80}{\text { Age }}$} \\
\hline Sex (male) & $56(70.0)$ \\
\hline BMI (kg/metre squared) & $28.33(5.6)^{a}$ \\
\hline iPTH (pmol/L) & $34.0(28.6)$ \\
\hline Serum Calcium (mmol/L) & $2.3(0.2)$ \\
\hline Serum Phosphate (mmol/L) & $1.7(0.4)$ \\
\hline LDL cholesterol (mmol/L) & $2.0(0.8)^{b}$ \\
\hline Time on dialysis (years) & $1.3(0.6,3.0)^{\mathrm{c}}$ \\
\hline Lifelong non-smoker & $26(32.5)$ \\
\hline Diabetes & $27(33.8)$ \\
\hline Serum Mg (mmol/L) & $0.84(0.2)$ \\
\hline Number of patients with low serum Mg & $26(32.5)$ \\
\hline Serum Albumin (g/L) & $32.4(4.5)$ \\
\hline $\mathrm{nPCR}$ (g/kg/day) & $0.8(0.2)$ \\
\hline $\mathrm{RRF}(\mathrm{mL} / \mathrm{min})$ & $4.7(3.8)$ \\
\hline $\begin{array}{l}\text { Number of patients on a cholesterol lowering medication } \\
\text { (statin or ezetemibe) }\end{array}$ & $55(68.8)$ \\
\hline Number of patients on APD & $62(77.5)$ \\
\hline Aortic calcification score & $8.9(6.9)$ \\
\hline \multicolumn{2}{|c|}{$\begin{array}{l}\text { Continuous measurements presented as mean (standard deviation (SD)), other } \\
\text { variables presented as } \mathrm{N}(\%) \text { unless otherwise specified } \\
B M I \text { body mass index, } i P T H \text { parathyroid hormone, } L D L \text { low density lipoprotein, } \\
M g \text { magnesium, } n P C R \text { normalized catabolic rate, } R R F \text { Residual renal function, } \\
A P D \text { automated peritoneal dialysis (the remainder of patients were on } \\
\text { continuous ambulatory peritoneal dialysis) } \\
\text { a Mean value for } 79 \text { patients ( } 1 \text { patient had a missing value) } \\
{ }^{\circ} \text { Mean value for } 75 \text { patients ( } 5 \text { patients had values that were missing or could } \\
\text { not be calculated) } \\
{ }^{c} \text { Median, interquartile range (IQR) }\end{array}$} \\
\hline
\end{tabular}

outlined in Table 1. The mean age of patients was 62.8 years, 56 patients $(70 \%)$ were male, $34 \%$ were diabetic and $33 \%$ were lifelong non-smokers. Mean serum $\mathrm{Mg}$ was $0.84 \mathrm{mmol} / \mathrm{L}$ (normal range 0.74 to $1.03 \mathrm{mmol} / \mathrm{L}$ ) and mean AAC score 8.9 (minimum score 0 , maximum score 24). The mean serum PO4 level was $1.70 \mathrm{mmol} / \mathrm{L}$ and mean LDL cholesterol $2.02 \mathrm{mmol} / \mathrm{L}$. The median time on dialysis was 1.3 years (IQR 0.6 to 3.0). Twenty six patients (32.5\%) had a low serum $\mathrm{Mg}$ (defined by $<0.74 \mathrm{mmol} / \mathrm{L}$ ), 42 patients $(52.5 \%)$ had a normal serum $\mathrm{Mg}$ and $12 \mathrm{pa}-$ tients (15.0\%) had a high serum $\mathrm{Mg}$ (defined as $>1.03 \mathrm{mmol} / \mathrm{L}$ ). Most patients $(77.5 \%)$ were on ambulatory peritoneal dialysis (APD). Included patients used the following PD fluid combinations: 1. Dianeal only in 19 (23.8\%) patients, 2. Extraneal only in $4(5.0 \%)$ patients, 3. Dianeal and Extraneal in 54 (67.5\%) patients, 4. Physioneal and Extraneal in $3(3.8 \%)$ patients.

\section{Univariate regression}

On univariate regression, age, serum phosphate, serum iPTH, LDL cholesterol, smoking history, diabetes, and 
Table 2 Univariate linear regression

\begin{tabular}{lllll}
\hline Variable & $R^{2}$ & Unstandardized coefficient (B) & $95 \%$ confidence interval (Cl) & $P$ value \\
\hline Age & 0.17 & 0.22 & $0.11,0.33$ & 0.00 \\
Sex & 0.005 & -1.04 & $-4.41,2.33$ & 0.54 \\
iPTH & 0.02 & 0.03 & $-0.02,0.09$ & 0.23 \\
Calcium & 0.00 & 0.04 & $-8.55,8.63$ & 0.99 \\
Phosphate & 0.07 & 4.52 & $0.91,8.13$ & 0.02 \\
LDL $^{\text {a }}$ & 0.07 & -2.19 & $-4.09,-0.29$ & 0.03 \\
Time on dialysis & 0.02 & -0.40 & $-1.10,0.30$ & 0.26 \\
Smoking history & 0.03 & 2.53 & $-0.73,5.79$ & 0.13 \\
Diabetes & 0.06 & 3.51 & $0.33,6.68$ & 0.03 \\
Albumin & 0.004 & -0.10 & $-0.45,0.24$ & 0.56 \\
RRF & 0.001 & -0.05 & $-0.46,0.37$ & 0.83 \\
Magnesium & 0.06 & -7.81 & $-15.01,-0.61$ & 0.03 \\
\hline
\end{tabular}

Smoking history (ex or current vs non-smoker)

iPTH intact parathyroid hormone

$L D L$ low-density lipoprotein

RRF Residual renal function

${ }^{a} 75$ patients included in the analysis for LDL ( 5 patients had values that were missing or could not be calculated). 80 patients included for all other variables

serum $\mathrm{Mg}$ had a $p$ value $\leq 0.2$. Older age, a higher serum PO4, a lower serum $\mathrm{Mg}$ and a history of diabetes were significantly associated with an increased AAC score $(p<0.05)$. Higher LDL cholesterol was associated with a decreased AAC score $(p=0.03)$ (Table 2).

\section{Multiple linear regression}

After adjustment for age, serum phosphate, serum iPTH, LDL cholesterol, smoking history, and diabetes, a lower serum $\mathrm{Mg}$ level was independently associated with a higher AAC score (Unstandardized coefficient $[\mathrm{B}]=-10.98$, $p=0.000)$. This statistic translates to a $0.1 \mathrm{mmol} / \mathrm{L}$ increase in serum $\mathrm{Mg}$ being associated with a 1.1-point decrease in AAC score. When all pre-specified variables (Table 2) were maintained in the model regardless of the univariate analysis $p$ value, the results were similar (B for $\mathrm{Mg}=-11.50, p=0.000)$. When patients with an AAC score of 0 were excluded, $n=68$ patients included in the analysis, the results were similar ( $\mathrm{B}$ for $\mathrm{Mg}=-12.27$, $p=0.001$ ) (Table 3). Testing assumptions of the linear regression model can be found in Additional file 1.

\section{Discussion}

Our data demonstrate that in PD patients, a lower serum $\mathrm{Mg}$ is independently associated with an increased AAC score. We found that a $0.1 \mathrm{mmol} / \mathrm{L}$ increase in serum $\mathrm{Mg}$ is associated with a 1.1-point decrease in AAC score. This suggests that $\mathrm{Mg}$ may act as a possible inhibitor of vascular calcification.

Our study results are consistent with previously published observational and pilot studies in the dialysis and chronic kidney disease populations [9, 13-19]. A recent cohort study with a maximum follow up of 10.8 years found that a lower serum Mg was associated with increased mortality in PD patients [23]. Several other studies have demonstrated an association between lower serum $\mathrm{Mg}$ and mortality among dialysis patients [21, 22, 24-27] This association could potentially be attributable to low serum $\mathrm{Mg}$ causing accelerated vascular calcification. Increasing data from in-vitro and animal studies support the assertion that $\mathrm{Mg}$ acts as an inhibitor of vascular calcification [6-12]. The addition of $\mathrm{Mg}$ to vascular smooth muscle cells increases the expression of anti-calcification proteins, such as matrix G1a, bone morphogenetic protein-7 and osteopontin, and

Table 3 Multiple linear regression: the independent association of serum Mg with vascular calcification

\begin{tabular}{lcccc}
\hline Model & Adjusted $R^{2}$ of the model & Unstandardized coefficient (B) for Mg & $95 \% \mathrm{Cl}$ & $P$ value \\
\hline 1 & 0.34 & -10.98 & $-17.40,-4.56$ & 0.000 \\
2 & 0.35 & -11.50 & $-17.93,-5.06$ & 0.000 \\
3 & 0.18 & -12.27 & $-19.54,-5.00$ & 0.001 \\
\hline
\end{tabular}

Model 1: Adjusted for age, serum phosphate, LDL cholesterol, iPTH, smoking history, and diabetes

Model 2: All pre-specified variables in Table 2 were included in the model

Model 3: Adjusted for the variables in model 1; patients with an aortic calcification score of $0(N=12)$ excluded from the analysis

Abbreviations: LDL low density lipoprotein cholesterol, iPTH intact parathyroid hormone 
inhibits an osteoblastic transformation [7, 11]. As well, the addition of $\mathrm{Mg}$ to vascular smooth muscle cells downregulates the $\mathrm{Wnt} / \beta$-catenin pathway. This pathway is essential for the osteogenic transformation of pluripotent mesenchymal cells and is activated during the development of vascular calcification [11]. The mechanism by which $\mathrm{Mg}$ regulates vascular calcification may involve the transient receptor potential melastin (TRPM)7 cation channel as inhibition of TRPM7 negates the anti-calcification effects of $\mathrm{Mg}$ $[7,11]$. Mg may also inhibit vascular calcification by suppressing PTH, which has been found in animal models to increase vascular calcification [36, 37]. Among PD patients, an inverse correlation between PTH and serum Mg, independent of $\mathrm{Ca}$ concentration, has been demonstrated in several studies [38-41]. However, in our cohort of PD patients, we did not find a significant, independent association between serum Mg and PTH (data not shown). To our knowledge, our study is the largest thus far in the PD population (previously published PD study $n=44$; outcome of peripheral arterial calcification [16]), and the largest study with a vascular calcification outcome that is a validated surrogate for $\mathrm{CAC}$.

AAC is a valid surrogate marker as it correlates with $\mathrm{CAC}$ and is associated with increased all-cause and cardiovascular mortality [28, 42, 43]. Among diabetic patients, reported hazard ratios for all-cause and cardiovascular mortality were 1.7 and 1.9 respectively when the AAC score was examined as a continuous variable [42]. Cardiovascular mortality has also been found to increase in a graded fashion with increasing tertile of AAC score [43].

Our study population had a mean serum $\mathrm{Mg}$ of $0.84 \mathrm{mmol} / \mathrm{L}$, and over $32 \%$ of our cohort had low serum $\mathrm{Mg}$ (defined as $<0.74 \mathrm{mmol} / \mathrm{L}$ ). The mean serum $\mathrm{Mg}$ was similar in a study by Fein et al. $(0.8 \mathrm{mmol} / \mathrm{L})$ examining the association of serum $\mathrm{Mg}$ with mortality in PD patients [23]. Comparatively, studies examining serum $\mathrm{Mg}$ in an $\mathrm{HD}$ population found a higher mean $\mathrm{Mg}$ level of $1.14 \mathrm{mmol} / \mathrm{L}$ [24], $0.92 \mathrm{mmol} / \mathrm{L}$ [26], and $0.86 \mathrm{mmol} / \mathrm{L}$ [21]. The high prevalence of hypomagnesemia in our cohort of PD patients could be due to the continuous nature of $\mathrm{PD}$, coupled with the low magnesium concentration of commonly used PD solutions ( $\mathrm{Mg}$ concentration ranging from 0.25 to $0.75 \mathrm{mmol} / \mathrm{L}$ ). Patients on automated PD overnight using a PD solution containing $0.25 \mathrm{mmol} / \mathrm{L}$ of $\mathrm{Mg}$ along with a day time dwell of an icodextrin solution, (the most commonly used regimen at our institution), have an overall transperitoneal $\mathrm{Mg}$ loss of $3.26 \mathrm{mmol}$ per $24 \mathrm{~h} \mathrm{[29].} \mathrm{Magnesium} \mathrm{losses} \mathrm{in} \mathrm{the} \mathrm{di-}$ alysate are compounded by the significant restrictions of a renal diet. Taken together, this highlights the unique risk of hypomagnesermia in PD patients, making them an ideal population for testing interventions targeted at increasing serum $\mathrm{Mg}$ and examining the effect on vascular calcification.
Our study has some important limitations. Due to the cross-sectional nature of the study, we can only determine association and not causation. Residual confounding is possible. However, we were able to adjust for important confounders associated with vascular calcification, such as serum $\mathrm{PO} 4$ and age [3], and our findings were consistent across unadjusted, adjusted and sensitivity analyses. A low serum $\mathrm{Mg}$ may be a marker of generalized malnutrition $[44,45]$ and inflammation, which are both associated with increased vascular calcification [46, 47]. We did not directly measure any inflammatory markers; however, albumin is a recognized surrogate for inflammation and malnutrition. On univariate analysis, albumin was not associated with the AAC score, and the results of the multivariate analysis were not attenuated upon adjustment for albumin. We only measured serum Mg at one time point; it is possible that a single measurement may not be reflective of an individual's overall Mg status. The imaging technique used in our study did not allow us to reliably differentiate between medial (AIM) and intimal calcification (AIC). Both types of vascular calcification occur commonly in dialysis patients, often co-existing in the same patient, and are associated with increased mortality. However, among dialysis patients, AIC has been found to be associated with worse survival when compared to AIM. As well, the clinical consequences of AIC and AIM differ. While AIC represents advanced atherosclerosis that is associated with the development of plaques and occlusive disease, AIM causes arterial stiffness, increased pulse pressure and left ventricular hypertrophy $[4,48,49]$.

\section{Conclusions}

In conclusion, our results support the assertion that $\mathrm{Mg}$ may inhibit vascular calcification, a condition that is highly prevalent in the dialysis population and is associated with increased mortality [2-4]. If our results can be duplicated in large observational studies with repeated serum $\mathrm{Mg}$ and vascular calcification measurements, interventions, such as $\mathrm{Mg}$ supplementation in hypomagnesemic patients, the use of $\mathrm{Mg}$ based phosphate binders, or the use of PD solutions with a higher $\mathrm{Mg}$ concentration and their effect on vascular calcification warrant testing in the PD population. Such interventions would be easy to administer and would carry minimal side effects.

\section{Additional file}

Additional file 1: Testing assumptions of the linear regression model. (DOCX $101 \mathrm{~kb}$ )

\section{Abbreviations}

AAC: Abdominal aortic calcification; APD: Ambulatory peritoneal dialysis; Ca: Calcium; CAC: Coronary artery calcification; HD: Hemodialysis; ICC: Intra-class correlation; LDL: Low density lipoprotein; Mg: Magnesium; 
PD: Peritoneal dialysis; PO4: Phosphate; TRPM7: The transient receptor potential melastin

\section{Acknowledgements}

AOM received salary support from the KRESCENT Foundation. AOM, BM and DZ receive salary support form the University of Ottawa Department of Medicine.

The results presented in this paper have not been published previously in whole or part, except in abstract form.

\section{Funding}

None to declare.

\section{Availability of data and materials}

The data used and/or analyzed during the current study are available from the corresponding author upon reasonable request.

\section{Authors' contributions}

M.B. and S.L. contributed to revising the article and the final approval of the version to be published. I.H. read patient radiographs, revised and contributed to the article and had final approval of the version to be published. EPF read patient radiographs, revised and contributed to the article and had final approval of the version to be published. B.M. revised the article, provided intellectual content and had final approval of the version to be published. M.M.S. helped with the analysis and interpretation of the data, revising the article and provided final approval of the version to be published. J.W. and J.P.H. helped with the collection of data, revising the manuscript and final approval of the version to be published. D.L.Z. and A.O.M. helped with the conception, design, analysis and interpretation of the data, drafting and revising of the article, providing intellectual content and final approval of the version to be published.

\section{Competing interests}

$\mathrm{BM}$ has the following disclosures that are unrelated to this submission: Baxter-consulting, speaker board, research grant; Concert Pharmaceuticalsconsulting; Sanofi- Advisory board. DZ has the following disclosure unrelated to this submission: Baxter- research grant. All other authors declare that they have no competing interests.

\section{Consent for publication}

Not applicable.

\section{Ethics approval and consent to participate}

Our study was conducted according to a pre-specified protocol approved by the Institutional Review Board at the Ottawa Hospital Research Institute $(20120175-01 \mathrm{H})$ and followed the Declaration of Helsinki. All patients provided informed consent.

\section{Publisher's Note}

Springer Nature remains neutral with regard to jurisdictional claims in published maps and institutional affiliations.

\section{Author details \\ 'Division of Nephrology, Department of Medicine, McMaster University, Hamilton, ON, Canada. ²Department of Radiology, University of Ottawa, Ottawa, ON, Canada. ${ }^{3}$ Department of Medical Imaging, The Ottawa Hospital Ottawa, Ottawa, ON, Canada. ${ }^{4}$ Division of Nephrology, Department of Medicine, Northern Ontario School of Medicine, Sudbury, ON, Canada. ${ }^{5}$ Kidney Research Centre, Ottawa Hospital Research Institute, Ottawa, ON, Canada. ${ }^{6}$ The Ottawa Hospital, Riverside Campus 1967 Riverside Drive, Ottawa, ON, CanadaK1H 7W9.}

\section{Received: 8 December 2015 Accepted: 3 April 2017}

\section{Published online: 06 April 2017}

\section{References}

1. Block GA, Klassen PS, Lazarus JM, Ofsthun N, Lowrie EG, Chertow GM. Mineral metabolism, mortality, and morbidity in maintenance hemodialysis. J Am Soc Nephrol. 2004;15:2208-18.

2. Parfrey PS, Foley RN. The clinical epidemiology of cardiac disease in chronic renal failure. J Am Soc Nephrol. 1999;10:1606-15.
3. Ketteler M, Biggar PH. Review article: getting the balance right: assessing causes and extent of vascular calcification in chronic kidney disease. Nephrology (Carlton). 2009;14:389-94.

4. London GM, Guerin AP, Marchais SJ, Metivier F, Pannier B, Adda H. Arterial media calcification in end-stage renal disease: impact on all-cause and cardiovascular mortality. Nephrol Dial Transplant. 2003;18:1731-40.

5. Kalpakian MA, Mehrotra R. Vascular calcification and disordered mineral metabolism in dialysis patients. Semin Dial. 2007;20:139-43.

6. Inagaki O, Syono T, Nakagawa K, Nishian Y, Takenaka Y, Takamitsu Y. Influence of magnesium deficiency on concentration of calcium in soft tissue of uremic rats. Ren Fail. 1996;18:847-54.

7. Montezano AC, Zimmerman D, Yusuf H, Burger D, Chignalia AZ, Wadhera V, van Leeuwen FN, Touyz RM. Vascular smooth muscle cell differentiation to an osteogenic phenotype involves TRPM7 modulation by magnesium. Hypertension. 2010;56:453-62.

8. Kircelli F, Peter ME, Sevinc Ok E, Celenk FG, Yilmaz M, Steppan S, Asci $\mathrm{G}$, Ok E, Passlick-Deetjen J. Magnesium reduces calcification in bovine vascular smooth muscle cells in a dose-dependent manner. Nephrol Dial Transplant. 2012;27:514-21.

9. Salem S, Bruck H, Bahlmann FH, Peter M, Passlick-Deetjen J, Kretschmer A, Steppan S, Volsek M, Kribben A, Nierhaus M, et al. Relationship between magnesium and clinical biomarkers on inhibition of vascular calcification. Am J Nephrol. 2012;35:31-9.

10. Louvet L, Buchel J, Steppan S, Passlick-Deetjen J, Massy ZA. Magnesium prevents phosphate-induced calcification in human aortic vascular smooth muscle cells. Nephrol Dial Transplant. 2013;28:869-78.

11. Montes de Oca A, Guerrero F, Martinez-Moreno JM, Madueno JA, Herencia C, Peralta A, Almaden Y, Lopez I, Aguilera-Tejero E, Gundlach K, et al. Magnesium inhibits Wnt/beta-catenin activity and reverses the osteogenic transformation of vascular smooth muscle cells. PLoS One. 2014;9:e89525.

12. Xu J, Bai Y, Jin J, Zhang J, Zhang S, Cui L, Zhang H. Magnesium modulates the expression levels of calcification-associated factors to inhibit calcification in a time-dependent manner. Exp Ther Med. 2015;9:1028-34.

13. Ishimura E, Okuno S, Kitatani K, Tsuchida T, Yamakawa T, Shioi A, Inaba M, Nishizawa Y. Significant association between the presence of peripheral vascular calcification and lower serum magnesium in hemodialysis patients. Clin Nephrol. 2007;68:222-7.

14. Tzanakis I, Pras A, Kounali D, Mamali V, Kartsonakis V, Mayopoulou-Symvoulidou D, Kallivretakis N. Mitral annular calcifications in haemodialysis patients: a possible protective role of magnesium. Nephrol Dial Transplant. 1997;12:2036-7.

15. Tzanakis I, Virvidakis K, Tsomi A, Mantakas E, Girousis N, Karefyllakis N, Papadaki A, Kallivretakis N, Mountokalakis T. Intra- and extracellular magnesium levels and atheromatosis in haemodialysis patients. Magnes Res. 2004;17:102-8.

16. Meema HE, Oreopoulos DG, Rapoport A. Serum magnesium level and arterial calcification in end-stage renal disease. Kidney Int. 1987;32:388-94.

17. Spiegel DM, Farmer B. Long-term effects of magnesium carbonate on coronary artery calcification and bone mineral density in hemodialysis patients: a pilot study. Hemodial Int. 2009;13:453-9.

18. Turgut F, Kanbay M, Metin MR, Uz E, Akcay A, Covic A. Magnesium supplementation helps to improve carotid intima media thickness in patients on hemodialysis. Int Urol Nephrol. 2008:40:1075-82.

19. Tzanakis IP, Stamataki EE, Papadaki AN, Giannakis N, Damianakis NE, Oreopoulos DG. Magnesium retards the progress of the arterial calcifications in hemodialysis patients: a pilot study. Int Urol Nephrol. 2014:46:2199-205

20. Sakaguchi Y, Fujii N, Shoji T, Hayashi T, Rakugi H, Iseki K, Tsubakihara Y, Isaka Y, Committee of Renal Data Registry of the Japanese Society for Dialysis T. Magnesium modifies the cardiovascular mortality risk associated with hyperphosphatemia in patients undergoing hemodialysis: a cohort study. PLoS One. 2014;9, e116273.

21. Li L, Streja E, Rhee CM, Mehrotra R, Soohoo M, Brunelli SM, Kovesdy CP, Kalantar-Zadeh K. Hypomagnesemia and mortality in incident hemodialysis patients. Am J Kidney Dis. 2015;66:1047-55.

22. de Roij van Zuijdewijn CL, Grooteman MP, Bots ML, Blankestijn PJ, Steppan S, Buchel J, Groenwold RH, Brandenburg V, van den Dorpel MA, Ter Wee PM, et al. Serum magnesium and sudden death in European hemodialysis patients. PLoS One. 2015;10, e0143104.

23. Fein P, Weiss S, Ramos F, Singh P, Chattopadhyay J, Avram MM. Serum magnesium concentration is a significant predictor of mortality in peritoneal dialysis patients. Adv Perit Dial. 2014;30:90-3. 
24. Ishimura E, Okuno S, Yamakawa T, Inaba M, Nishizawa Y. Serum magnesium concentration is a significant predictor of mortality in maintenance hemodialysis patients. Magnes Res. 2007;20:237-44.

25. Joao Matias P, Azevedo A, Laranjinha I, Navarro D, Mendes M, Ferreira C, Amaral T, Jorge C, Aires I, Gil C, et al. Lower serum magnesium is associated with cardiovascular risk factors and mortality in haemodialysis patients. Blood Purif. 2014;38:244-52.

26. Lacson Jr E, Wang W, Ma L, Passlick-Deetjen J. Serum magnesium and mortality in hemodialysis patients in the United States: a cohort study. Am J Kidney Dis. 2015;66:1056-66.

27. Cai K, Luo Q, Dai Z, Zhu B, Fei J, Xue C, Wu D. Hypomagnesemia is associated with increased mortality among peritoneal dialysis patients. PLOS One. 2016;11, e0152488.

28. Bellasi A, Ferramosca E, Muntner P, Ratti C, Wildman RP, Block GA, Raggi P. Correlation of simple imaging tests and coronary artery calcium measured by computed tomography in hemodialysis patients. Kidney Int. 2006;70:1623-8.

29. Eddington $\mathrm{H}$, Hurst $\mathrm{H}$, Ramli MT, Speake M, Hutchison AJ. Calcium and magnesium flux in automated peritoneal dialysis. Perit Dial Int. 2009;29:536-41.

30. Ejaz AA, McShane AP, Gandhi VC, Leehey DJ, Ing TS. Hypomagnesemia in continuous ambulatory peritoneal dialysis patients dialyzed with a lowmagnesium peritoneal dialysis solution. Perit Dial Int. 1995;15:61-4.

31. Kauppila LI, Polak JF, Cupples LA, Hannan MT, Kiel DP, Wilson PW. New indices to classify location, severity and progression of calcific lesions in the abdominal aorta: a 25-year follow-up study. Atherosclerosis. 1997;132:245-50.

32. Blake PG, Bargman JM, Brimble KS, Davison SN, Hirsch D, McCormick BB, Suri RS, Taylor P, Zalunardo N, Tonelli M, et al. Clinical practice guidelines and recommendations on peritoneal dialysis adequacy 2011. Perit Dial Int. 2011:31:218-39.

33. Bellasi A, Kooienga L, Block GA, Veledar E, Spiegel DM, Raggi P. How long is the warranty period for nil or low coronary artery calcium in patients new to hemodialysis? J Nephrol. 2009;22:255-62.

34. Block GA, Spiegel DM, Ehrlich J, Mehta R, Lindbergh J, Dreisbach A, Raggi P. Effects of sevelamer and calcium on coronary artery calcification in patients new to hemodialysis. Kidney Int. 2005;68:1815-24.

35. von Elm E, Altman DG, Egger M, Pocock SJ, Gotzsche PC, Vandenbroucke JP, Initiative S. The Strengthening the Reporting of Observational Studies in Epidemiology (STROBE) statement: guidelines for reporting observational studies. Lancet. 2007;370:1453-7.

36. Coen G. Calcimimetics, parathyroid hormone, and vascular calcification in chronic kidney disease. Kidney Int. 2008;74:1229-31.

37. Neves KR, Graciolli FG, dos Reis LM, Graciolli RG, Neves CL, Magalhaes AO, Custodio MR, Batista DG, Jorgetti V, Moyses RM. Vascular calcification: contribution of parathyroid hormone in renal failure. Kidney Int. 2007;71:1262-70.

38. Navarro JF, Mora C, Garcia J, Macia M, Gallego E, Chahin J, Mendez ML, Rivero A. Hypermagnesemia in CAPD. Relationship with parathyroid hormone levels. Perit Dial Int. 1998;18:77-80.

39. Navarro JF, Mora C, Macia M, Garcia J. Serum magnesium concentration is an independent predictor of parathyroid hormone levels in peritoneal dialysis patients. Perit Dial Int. 1999;19:455-61.

40. Saha HH, Harmoinen AP, Pasternack Al. Measurement of serum ionized magnesium in CAPD patients. Perit Dial Int. 1997;17:347-52.

41. Wei M, Esbaei K, Bargman JM, Oreopoulos DG. Inverse correlation between serum magnesium and parathyroid hormone in peritoneal dialysis patients: a contributing factor to adynamic bone disease? Int Urol Nephrol. 2006;38:317-22.

42. Cox AJ, Hsu FC, Agarwal S, Freedman BI, Herrington DM, Carr JJ, Bowden DW. Prediction of mortality using a multi-bed vascular calcification score in the Diabetes Heart Study. Cardiovasc Diabetol. 2014;13:160.

43. Wilson PW, Kauppila LI, O'Donnell CJ, Kiel DP, Hannan M, Polak JM, Cupples LA. Abdominal aortic calcific deposits are an important predictor of vascular morbidity and mortality. Circulation. 2001;103:1529-34.

44. Martin-del-Campo F, Batis-Ruvalcaba C, Gonzalez-Espinoza L, Rojas-Campos E, Angel JR, Ruiz N, Gonzalez J, Pazarin L, Cueto-Manzano AM. Dietary micronutrient intake in peritoneal dialysis patients: relationship with nutrition and inflammation status. Perit Dial Int. 2012;32:183-91.

45. Ye H, Zhang X, Guo Q, Huang N, Mao H, Yu X, Yang X. Prevalence and factors associated with hypomagnesemia in Southern Chinese continuous ambulatory peritoneal dialysis patients. Perit Dial Int. 2013;33:450-4.

46. An WS, Son YK. Vascular calcification on plain radiographs is associated with carotid intima media thickness, malnutrition and cardiovascular events in dialysis patients: a prospective observational study. BMC Nephrol. 2013;14:27.
47. Wang AY. Vascular and valvular calcification in chronic peritoneal dialysis patients. International journal of nephrology. 2011:2011:198045.

48. Nakamura S, Ishibashi-Ueda H, Niizuma S, Yoshihara F, Horio T, Kawano Y. Coronary calcification in patients with chronic kidney disease and coronary artery disease. Clin J Am Soc Nephrol. 2009;4:1892-900.

49. Amann K. Media calcification and intima calcification are distinct entities in chronic kidney disease. Clin J Am Soc Nephrol. 2008;3:1599-605.

\section{Submit your next manuscript to BioMed Central and we will help you at every step:}

- We accept pre-submission inquiries

- Our selector tool helps you to find the most relevant journal

- We provide round the clock customer support

- Convenient online submission

- Thorough peer review

- Inclusion in PubMed and all major indexing services

- Maximum visibility for your research

Submit your manuscript at www.biomedcentral.com/submit
Biomed Central 